\title{
Retraction Note to: Fate and Transport of EDCs in Soils: Estrone and its Sulfate Conjugate's Adsorption from Mediator Solutions
}

\author{
Alkali Mohammed • Y. S. Yang • X. Q. Du • A. Musa
}

Published online: 2 July 2013

(C) Springer Science+Business Media Dordrecht 2013

\section{Retraction to: Water Air Soil Pollut \\ DOI 10.1007/s11270-012-1432-x}

This article has been retracted following an investigation by the Editor-in-Chief of a complaint received against it. After consultation with the corresponding author, both the Editor in Chief and corresponding author have agreed that substantial portions of the text came from another paper without proper attribution. The article has therefore been retracted at the request of the Editor-in-Chief and corresponding author due to plagiarism.

The online version of the original article can be found at http:// dx.doi.org/10.1007/s11270-012-1432-x.

A. Mohammed · Y. S. Yang · X. Q. Du

Key Laboratory of Groundwater Resources and Environment, Ministry of Education, Jilin University,

Changchun 130021, People's Republic of China

Y. S. Yang $(\bowtie)$

School of Earth and Ocean Sciences, Cardiff University,

Cardiff CF10 3YE, UK

e-mail: yangy6@cf.ac.uk

\section{A. Musa}

Department of Agronomy and Soil Science,

Nasarawa State University,

PMB 1022 Keffi, Nigeria 